\title{
First Feasibility Study and Short-term Outcomes of Laparoscopic-Assisted Anterior Resection in Colorectal Cancer in Malaysia
}

\author{
Henry Chor Lip Tan ${ }^{1,2}$, Jih Huei Tan ${ }^{1,2}$, Nur Akmalrudin Nur Dzainuddin ${ }^{1}$, Koon Khee Chan ${ }^{1}$ \\ ${ }^{1}$ Colorectal Unit, Department of Surgery, Hospital Sultanah Aminah, Johor Bahru; ${ }^{2}$ Department of General Surgery, Faculty of Medicine, \\ National University of Malaysia Medical Centre, Kuala Lumpur, Malaysia
}

Purpose: The purpose of this study was to demonstrate the feasibility and safety of laparoscopic-assisted anterior resection (LAAR) for colorectal cancer in a local Asian population.

Methods: This is a retrospective review of all patients with colorectal cancer operated from November 2017 to October 2018. Main variables of interest were demography, type and surgery, length of stay (LOS), and the involvement of proximal and distal doughnut. Postoperative complications were analysed using chi-square or Fisher exact and Mann-Whitney tests. Results: There were 23 patients with a mean age of $62.5 \pm 12.2$ years. The mean time from diagnosis to surgery was $97.1 \pm$ 154.84 days. There were 12 patients in the LAAR group and 11 in the open anterior resection (OAR) group. Duration of surgery was shorter in OAR (129.58 \pm 51.38 minutes) compared to LAAR (147.91 \pm 39.37 minutes). Mean LOS was shorter in the LAAR group with $5 \pm 1.5$ days compared to the OAR group of $7.42 \pm 4.25$ days. However, there was no significant $\mathrm{P}$-value for both duration of surgery $(\mathrm{P}=0.322)$ or LOS $(\mathrm{P}=0.87)$. A total of 3 complications were recorded after OAR and 2 after LAAR. Both groups had clear proximal and distal margins with 16 (12-18.5) harvested lymph nodes in LAAR and $18(16-22)$ in OAR, which were equal $(\mathrm{P}=0.155)$.

Conclusion: This study reports a shorter LOS in the minimally invasive group of 2 days with similar oncologic resection outcomes. This shows that LAAR is feasible in Malaysia and has potential outcome benefits.

Keywords: Colorectal cancer; Colorectal surgery; Laparoscopic surgery

\section{INTRODUCTION}

Since the advent of laparoscopic colonic resections 2 decades ago, advances in technology have allowed more complex colorectal surgeries to be performed laparoscopically [1]. In the beginning, sceptics raised controversial issues, such as a possible increase in recurrence rates and port site recurrences, and the ability to retain

Received: March 26, 2019 - Accepted: May 10, 2019

Correspondence to: Henry Chor Lip Tan, M.D.

Colorectal Unit, Department of Surgery, Hospital Sultanah Aminah, Johor

Bahru, Malaysia

Tel: +60-137125014

E-mail: relos1402@gmail.com

ORCID: https://orcid.org/0000-0003-0621-9276

(C) 2020 The Korean Society of Coloproctology

This is an open-access article distributed under the terms of the Creative Commons Attribution NonCommercial License (https://creativecommons.org/licenses/by-nc/4.0) which permits unrestricted non-

commercial use, distribution, and reproduction in any medium, provided the original work is properly cited. proper oncologic resection principles was questioned [2]. However, minimally invasive or laparoscopic colonic surgeries have become a higher form of advanced surgery for colorectal surgeons in this current era. The skill in developing the dexterity, patience and ability to adhere to oncologic resection principles is the desired outcome of surgeons [3]. Since the beginning of laparoscopic colorectal surgery, positive reports on oncologic and survival outcomes have been reported in numerous international publications [4]. According to the COLOR II trial, laparoscopic and open surgery conferred similar long-term outcomes of 3-year local recurrence (5\% in both groups) and 5-year overall survival (74.8\% vs. 70.8\%) [5]. The short-term outcomes of laparoscopic surgery were reported by Martínez-Pérez et al. [6] in a systematic review, which included a shorter mean length of stay of 1.71 days $(\mathrm{P}<0.001)$ and earlier bowel recovery of 0.86 days $(\mathrm{P}<0.001)$. From our literature search, there were also multiple publications on Malaysian colorectal surgery data, but these reports were on 
open colorectal surgeries [7]. Therefore, this study was undertaken to examine the feasibility of laparoscopic colorectal surgeries performed in a Malaysian colorectal surgery unit. The objectives of this study were to describe the demography of patients presenting with colorectal cancer and compare the short-term outcomes of open anterior resection (OAR) with laparoscopic-assisted anterior resection (LAAR, postoperative and oncologic histopathology details). As previously mentioned, data on laparoscopic colorectal surgery in Malaysia is scarce [7]. Therefore, this data is equally important as an audit to compare our outcomes to international standards.

\section{MATERIALS AND METHODS}

\section{Study design/sample population}

This is a retrospective review of all patients who were diagnosed with sigmoid, rectosigmoid, upper rectal, or midrectal cancer undergoing elective LAAR or OAR at the Hospital Sultanah Aminah Colorectal Surgery Unit, Malaysia between October 2017 and November 2018.

\section{Patients}

All patients were examined with a colonoscopy, confirmed positive histology results of colorectal cancer, contrast computed tomography (CT) scan of thorax, abdomen, and pelvis for staging prior to surgery. After these examinations were performed, the results were evaluated by the colorectal consultant surgeon and the decision for upfront surgery or neo-adjuvant chemotherapy was made. Generally, preoperative chemotherapy was given to patients with fixed T4 disease. Laparoscopic resections were performed based on (1) the anticipated difficulty during laparoscopic surgery due to previous abdominal surgeries; (2) evidence of possible tumor infiltration to surrounding organs on the contrast CT scan and (3) the choice and preference of the patient. The surgical approach was decided by the surgeon and patient after understanding the risks and benefits of each procedure. The study was conducted in compliance with the ethical principles outlined in the Declaration of Helsinki and Malaysian Good Clinical Practice Guideline. Permission from the local Institutional Review Board, the hospital director and head of the Department of General Surgery was obtained prior to the collection of data. Ethical approval was granted by the Ministry of Health Malaysia Medical Research Ethics Committee (KKM/NIHSEC/P19-2163). As patient data were collected anonymously, informed consent was waived and not required. A flowchart showing inclusion and exclusion criteria is presented in Fig. 1.

\section{Operative techniques}

Surgical resections were classified as OAR or LAAR. The majority of the surgeries were performed by the sole consultant colorectal surgeon and the remainder of cases by the colorectal fellow in training under direct supervision. There have been numerous publications describing the operative technique for OAR and LAAR [8]. The fundamental principles of en bloc resection with curative intent for each procedure were strictly adhered [9]. Independent of the surgical approach, mobilization of the rectum and colon was performed with LigaSure (ValleyLab, Inc., Boulder, CO, USA) or Harmonic (Ethicon Endo-Surgery, Inc., Cincinnati, $\mathrm{OH}$,

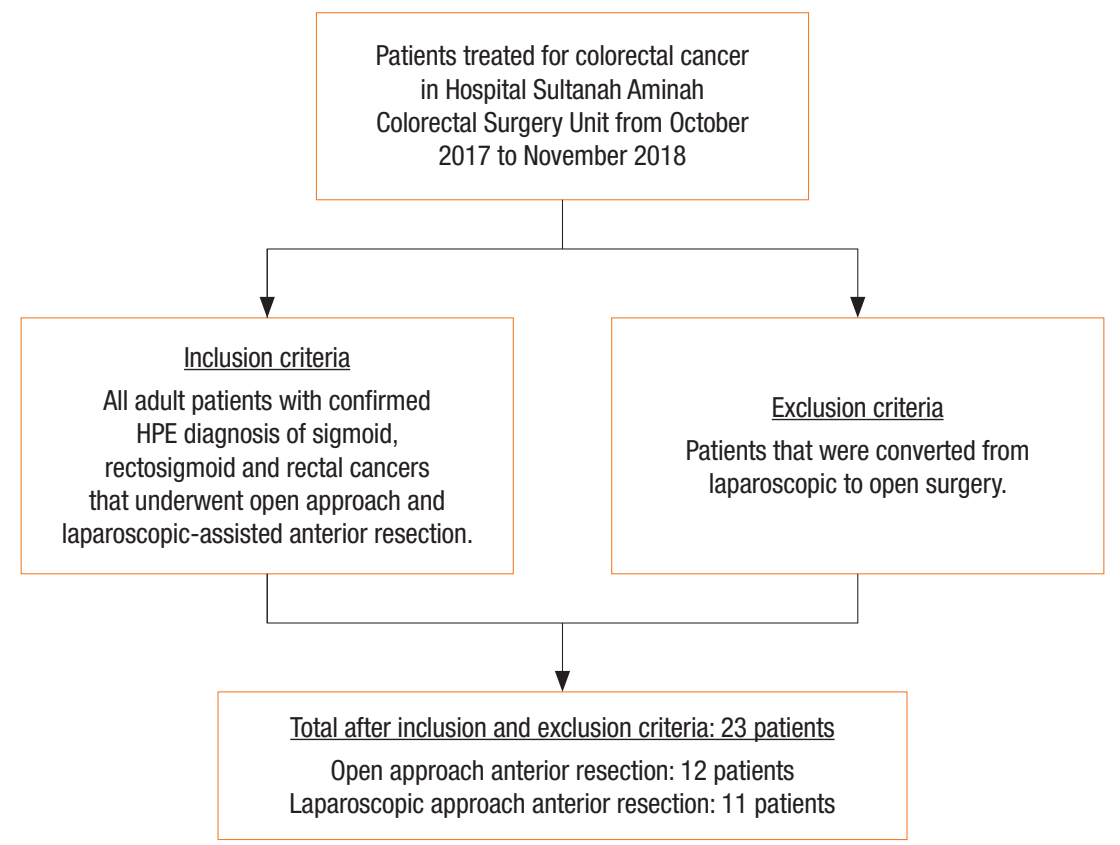

Fig. 1. Flow chart showing the inclusion and exclusion criteria for patient selection. HPE, histopathology examination. 
USA) for the laparoscopic approach and diathermy in the open approach. By using 4-trocars, the inferior mesenteric artery was ligated after identification of the left ureter followed by retromesenteric dissection using a medial to lateral route. For every case, we performed a high ligation of the inferior mesenteric artery taking the branch of the left colic vessels. However, if added length for a tension-free colorectal anastomosis was required, high ligation of the inferior mesenteric artery was performed at the level of the ligament of Treitz. The splenic flexure was later mobilized and followed by laparoscopic total mesorectum excision (TME) with preservation of the hypogastric plexus and nerves. A level of distal colonic transection with a gross estimation of at least $2 \mathrm{~cm}$ away from the tumor together with intact mesorectum was considered adequate. The rectum was transected with an endoscopic or conventional stapler through a low abdominal transverse incision. TME was performed in patients with midrectal cancer and partial mesorectal excision for more proximal tumors. Colorectal anastomosis was performed using a double-stapling technique and end-to-end anastomosis using Proximate ILS (Ethicon Endo-Surgery, Inc.) [10, 11]. Proximal diversion was not routinely performed on our patients and was only considered if the anastomosis was hazardous. All patients included had curative surgery which is defined as the removal of all macroscopic disease at the end of surgery [12]. For patients with distant metastatic disease, surgery was still considered curative if the synchronous metastases were completely removed in the same setting or in subsequent operations [13].

\section{Postoperative care}

In our centre, there is a strict adherence to the enhance recovery after surgery protocol [14]. All patients planned for elective colorectal surgery have to be reviewed by the physiotherapist and dietician teams. The role of the physiotherapist is to assess muscle strength and educate patients on early deep breathing exercises via incentive spirometry with other exercises according to individual patients. The role of the dietician was to assess the nutritional status of the patient and advise on the optimum polymeric diet prior to surgery. All patients were advised to wear thrombo-embolicdeterrent stockings starting from the day of admission for surgery. Bowel preparation was performed 2 days prior to surgery using Fortrans (Ipsen Pharma, Paris, France). On the day of surgery, patients were allowed nourishing fluids until 2 hours prior to surgery with Carborie (Valens Nutrition, Kuala Lumpur, Malaysia) loading 10 hours and 2 hours prior to surgery. If there were no complications, patients were allowed clear fluids on postoperative day 1 and titrated to full diet according to individual patients.

\section{Study parameters}

Parameters of interest were divided into patient demography, operative/postoperative details and histopathology variables. Patient demography included patients age, sex, race, source of referral, chief complaint, comorbidities, and any family history of colonic cancer. Operative/postoperative details were mean duration of surgery, length of stay, and postoperative complications. Histopathol-

Table 1. Comparison of demographic and preoperative details of open and laparoscopic surgery

\begin{tabular}{|c|c|c|c|c|}
\hline Variable & $\begin{array}{c}\text { Total } \\
(n=23)\end{array}$ & $\begin{array}{c}\text { OAR } \\
(n=12)\end{array}$ & $\begin{array}{c}\text { LAAR } \\
(n=11)\end{array}$ & P-value \\
\hline Age (yr) & $62.5 \pm 12.2$ & $60.92 \pm 10.98$ & $64.27 \pm 13.71$ & 0.504 \\
\hline Sex & & & & 0.554 \\
\hline Male & $16(69.6)$ & $9(75)$ & 7 (63.3) & \\
\hline Female & $7(30.4)$ & $3(25)$ & $4(36.4)$ & \\
\hline Race & & & & 0.555 \\
\hline Malay & $11(47.8)$ & 7 (58.3) & $4(36.4)$ & \\
\hline Chinese & $10(43.5)$ & $4(33.3)$ & $6(54.5)$ & \\
\hline Indian & $2(8.7)$ & $1(8.3)$ & $1(9.1)$ & \\
\hline Source of referral & & & & 0.792 \\
\hline $\begin{array}{l}\text { Primary health } \\
\text { clinic }\end{array}$ & $10(43.5)$ & $6(50)$ & $4(36.4)$ & \\
\hline District hospital & $2(8.7)$ & $1(8.3)$ & $1(9.1)$ & \\
\hline Tertiary hospital & $4(17.4)$ & $2(16.7)$ & $2(18.2)$ & \\
\hline Private hospital & $3(13)$ & $2(16.7)$ & $1(9.1)$ & \\
\hline Intradepartment & $4(17.4)$ & $1(8.3)$ & $3(27.3)$ & \\
\hline \multicolumn{5}{|l|}{ Symptoms } \\
\hline Rectal bleed & 18 (78.3) & $9(75)$ & $9(81.8)$ & 0.692 \\
\hline Abdominal pain & $5(21.7)$ & $2(16.7)$ & $3(27.3)$ & 0.538 \\
\hline Diarrhoea & $4(17.4)$ & $3(25)$ & $1(9.1)$ & 0.315 \\
\hline Constipation & $9(39.1)$ & $4(33.3)$ & $5(45.5)$ & 0.552 \\
\hline Loss of weight & $14(60.9)$ & $9(75)$ & $5(45.5)$ & 0.147 \\
\hline Loss of appetite & $14(60.9)$ & $9(75)$ & $5(45.5)$ & 0.147 \\
\hline $\begin{array}{l}\text { Abdominal } \\
\text { distension }\end{array}$ & $1(4.3)$ & $1(8.3)$ & $0(0)$ & 0.328 \\
\hline Abdominal mass & $1(4.3)$ & $1(8.3)$ & $0(0)$ & 0.286 \\
\hline Tenesmus & $1(4.3)$ & $0(0)$ & $1(9.1)$ & 0.286 \\
\hline CEA (ng/mL) & $7.9 \pm 12.4$ & $7.78 \pm 10.45$ & $8.03 \pm 14.85$ & 0.991 \\
\hline \multicolumn{5}{|l|}{ Comorbidities } \\
\hline Diabetes & $7(30.4)$ & $3(25)$ & $4(36.4)$ & 0.554 \\
\hline Hypertension & $11(47.8)$ & $5(47.7)$ & $6(54.5)$ & 0.537 \\
\hline $\begin{array}{l}\text { Cardiovascular } \\
\text { disease }\end{array}$ & $2(8.7)$ & $1(8.3)$ & $1(9.1)$ & 0.949 \\
\hline $\begin{array}{l}\text { Respiratory } \\
\text { disease }\end{array}$ & $3(13)$ & $1(8.3)$ & $2(18.2)$ & 0.484 \\
\hline Others & $5(21.7)$ & $3(25)$ & $2(18.2)$ & 0.692 \\
\hline Smoking & $5(21.7)$ & $4(33.3)$ & $1(9.1)$ & 0.159 \\
\hline $\begin{array}{l}\text { Family history of } \\
\text { colonic cancer }\end{array}$ & $5(21.7)$ & $2(16.7)$ & $3(27.3)$ & 0.538 \\
\hline
\end{tabular}

Values are presented as mean \pm standard deviation or number (\%).

$\mathrm{OAR}$, open anterior resection; LAAR, laparoscopic-assisted anterior resection; CEA, carcinoembryonic antigen. 
ogy variables of interest were type of cancer, tumor differentiation, lymphatic invasion, proximal, distal, and circumferential margin.

\section{Statistical analyses}

Data were analysed using SPSS ver. 16.0 (SPSS Inc, Chicago, IL, USA). All continuous variables were expressed as median with interquartile range and categorical variables were expressed as frequencies and percentages. Each variable was tested for differences between OAR and LAAR using univariate analysis. Categorical data were analysed with chi-square or Fisher exact tests when more than $20 \%$ of cells had expected frequencies $<5$ and continuous variables were analysed with the Mann-Whitney test. All P-values less than 0.05 were considered statistically significant.

\section{RESULTS}

In a 1-year period, we identified 23 patients which were included in this study and were predominantly male (69.6\%) with a mean age of $62.5 \pm 12.2$ years. Open surgery was performed in 12 patients (52.2\%) and 11 patients (47.8\%) underwent LAAR. Comparisons of demographic and preoperative details between open and laparoscopic anterior resection are presented in Table 1. There was no statistical significance in the differences between demographic and preoperative details of these 2 groups. There was an almost equal distribution between Malay (47.8\%) and Chinese patients (43.5\%), which make up the major ethnic races in Malaysia. Leading sources of patient referrals were from the primary health clinic (43.5\%) with cardinal symptoms of rectal bleeding. Hypertension and diabetes were the 2 most commonly encountered comorbidities in the sample population.

Comparison of surgery details revealed no statistical significance in the parameters of interest as seen in Table 2. There was an equal number of assistants in terms of ranks from surgeons, gazetting surgeon, registrar, medical officers, and house officers. In both laparoscopic and open surgery, there was a mean of 2 assistants. Although there was no statistical significance, patients in the laparoscopic group had a longer mean time of surgery (147.91 \pm 39.37 minutes) versus open surgery (129.58 \pm 51.38 minutes). However, patients in the laparoscopic surgery group had a shorter duration of stay ( $5 \pm 1.55$ days) compared to patients who had open surgery ( $7.42 \pm 4.25$ days). The number of patients readmitted after discharge from the ward was equal and complication rates were similar (Table 2). There were 2 patients with an anastomotic leak, both from the OAR group, which accounts for the anastomotic leak rate of $4.3 \%$ found in Table 3.

Histologic details also revealed no statistical significance in a

Table 3. Postoperative outcomes

\begin{tabular}{lcccc}
\hline Variable & Total $(\mathrm{n}=23)$ & OAR $(\mathrm{n}=12)$ & LAAR $(\mathrm{n}=11)$ & P-value \\
\hline Length of stay (day) & $6.26 \pm 3.41$ & $7.42 \pm 4.25$ & $5.00 \pm 1.55$ & 0.87 \\
$\begin{array}{l}\text { Postoperative } \\
\text { readmission }\end{array}$ & $4(17.4)$ & $2(16.7)$ & $2(18.2)$ & \\
$\begin{array}{l}\text { Days to readmission } \\
\text { Complications }\end{array}$ & $27 \pm 14.5$ & $12 \pm 7.07$ & $17 \pm 14.14$ & 0.924 \\
$\quad$ Anastomotic leak & $2(8.7)$ & $3(25)$ & $2(18.2)$ & \\
$\begin{array}{c}\text { Superficial surgical } \\
\text { site infection }\end{array}$ & $1(4.3)$ & $0(0)$ & $1(9.1)$ & \\
$\begin{array}{c}\text { Deep surgical site } \\
\text { infection }\end{array}$ & $1(4.3)$ & $1(8.3)$ & $0(0)$ \\
$\begin{array}{l}\text { Enterocutaneous } \\
\text { Fistula }\end{array}$ & $1(4.3)$ & $0(0)$ & $1(9.1)$ & \\
\hline
\end{tabular}

Values are presented as mean \pm standard deviation or number (\%).

OAR, open anterior resection; LAAR, laparoscopic-assisted anterior resection.

Table 2. Comparison of surgery details of laparoscopic-assisted and open anterior resection

\begin{tabular}{lccc}
\hline Variable & Total $(\mathrm{n}=23)$ & OAR $(\mathrm{n}=12)$ & LAAR $(\mathrm{n}=11)$ \\
\hline Time from first visit to surgery (day) & $97.09 \pm 154.84$ & $77.83 \pm 90.34$ & $118.1 \pm 205.98$ \\
Time of surgery (min) & $138.35 \pm 45.96$ & $129.58 \pm 51.38$ & $147.91 \pm 39.37$ \\
Primary surgeon & & & \\
Colorectal surgeon & $20(87)$ & $11(91.7)$ & 9.195 \\
$\quad$ Colorectal trainee & $3(13)$ & $1(8.3)$ & $2(18.2)$ \\
No. of intraoperative assistants & $2.2 \pm 0.6$ & $2.1 \pm 0.6$ & $2.2 \pm 0.6$ \\
Level of assistants & & & $7(63.6)$ \\
Surgeon & $13(56.5)$ & $6(50)$ & $6(54.5)$ \\
Surgeon in gazettement & $9(39.1)$ & $3(25)$ & $7(63.6)$ \\
Registrar & $13(56.5)$ & $6(50)$ & $6(54.5)$ \\
Medical officer & $14(60.9)$ & $8(66.7)$ & $2(18.2)$ \\
House officer & $4(17.4)$ & $2(16.7)$ & \\
\hline
\end{tabular}

Values are presented as mean \pm standard deviation or number (\%).

OAR, open anterior resection; LAAR, laparoscopic-assisted anterior resection. 
Table 4. Histopathological details

\begin{tabular}{|c|c|c|c|c|}
\hline Variable & Total $(n=23)$ & OAR $(n=12)$ & LAAR $(n=11)$ & P-value \\
\hline \multicolumn{5}{|l|}{ Tumor location } \\
\hline Sigmoid colon & $8(34.8)$ & $4(33.3)$ & $4(36.4)$ & \\
\hline Rectosigmoid junction & $2(8.7)$ & $1(8.3)$ & $1(9.1)$ & \\
\hline Upper rectum & $11(47.8)$ & $5(41.7)$ & $6(54.5)$ & 0.399 \\
\hline Mid rectum & $1(4.3)$ & $1(8.3)$ & $0(0)$ & \\
\hline Lower rectum & $1(4.3)$ & $1(8.3)$ & $0(0)$ & \\
\hline Adenocarcinoma & $23(100)$ & $12(100)$ & $11(100)$ & \\
\hline Tumor differentiation & & & & 0.283 \\
\hline Well & $6(26.1)$ & $2(16.7)$ & $4(36.4)$ & \\
\hline Moderate & $17(73.1)$ & 10 (83.3) & 7 (63.6) & \\
\hline Poor & $0(0)$ & $0(0)$ & $0(0)$ & \\
\hline Lymphatic invasion & & & & 0.469 \\
\hline Yes & $8(34.8)$ & $5(41.7)$ & $3(27.3)$ & \\
\hline No & $15(65.2)$ & $7(58.3)$ & $8(727)$ & \\
\hline $\begin{array}{l}\text { Peritumoral lymphoid } \\
\text { reaction }\end{array}$ & & & & 0.836 \\
\hline No & $10(43.5)$ & $4(33.3)$ & $6(54.5)$ & \\
\hline Mild & $10(43.5)$ & $8(66.7)$ & $2(18.2)$ & \\
\hline Marked & $3(13)$ & $0(0)$ & $3(27.3)$ & \\
\hline Perineural Invasion & & & & 0.949 \\
\hline Yes & $2(8.7)$ & $1(8.3)$ & $1(9.1)$ & \\
\hline No & $21(91.3)$ & $11(91.7)$ & $10(90.9)$ & \\
\hline Harvested lymph nodes* & $17(14-19.5)$ & 18 (16-22) & $16(12-18.5)$ & 0.155 \\
\hline Positive lymph nodes* & $0(0-2)$ & $0(0-1.5)$ & $0(1-2)$ & 0.971 \\
\hline \multicolumn{5}{|l|}{ Pathological staging } \\
\hline Primary tumor (T) & & & & 0.461 \\
\hline $\mathrm{T} 1$ & $2(8.7)$ & $0(0)$ & $2(18.2)$ & \\
\hline $\mathrm{T} 2$ & $3(13)$ & $2(16.7)$ & $1(9.1)$ & \\
\hline T3 & $14(60.9)$ & $8(66.7)$ & $6(54.5)$ & \\
\hline T4a & $3(13)$ & $2(16.7)$ & $1(9.1)$ & \\
\hline$T 4 b$ & $1(4.3)$ & $0(0)$ & $1(9.1)$ & \\
\hline
\end{tabular}

comparison of major parameters (Table 4). All patients in the sample population had a primary histologic diagnosis of adenocarcinoma. Interestingly, there was no difference between the proximal $(6.3 \mathrm{~cm}$ in the open group vs. $5.0 \mathrm{~cm}$ in the laparoscopic group) and distal resection margins (3.3 in the open group vs. 3 $\mathrm{cm}$ in the laparoscopic group). The circumferential radial margin was sufficient both in the laparoscopic group $(2.0 \mathrm{~mm})$ and the open group ( $1.6 \mathrm{~mm})$. There was a total of 8 sigmoid (5 OAR and 3 LAAR) and 2 rectosigmoid ( 1 OAR and 1 LAAR) cancers. The mean proximal and distal margins for sigmoid cancers in OAR
Table 4. Continued

\begin{tabular}{|c|c|c|c|c|}
\hline Variable & Total $(n=23)$ & OAR $(n=12)$ & $\operatorname{LAAR}(\mathrm{n}=11)$ & P-value \\
\hline $\begin{array}{l}\text { Regional lymph nodes } \\
\text { (N) }\end{array}$ & & & & 0.757 \\
\hline NO & 15 (65.2) & $8(66.7)$ & 7 (63.6) & \\
\hline $\mathrm{N} 1 \mathrm{a}$ & $2(8.7)$ & $1(8.3)$ & $1(9.1)$ & \\
\hline N1b & $3(13)$ & $1(8.3)$ & $2(18.2)$ & \\
\hline $\mathrm{N} 1 \mathrm{C}$ & $0(0)$ & $0(0)$ & $0(0)$ & \\
\hline N2a & $1(4.3)$ & $1(8.3)$ & $0(0)$ & \\
\hline $\mathrm{N} 2 \mathrm{~b}$ & $2(8.7)$ & $1(8.3)$ & $1(9.1)$ & \\
\hline Distant metastasis (M) & & & & 0.478 \\
\hline M0 & $22(95.7)$ & $12(100)$ & 10 (90.9) & \\
\hline M1a & $1(4.3)$ & $0(0)$ & $1(9.1)$ & \\
\hline M1b & $0(0)$ & $0(0)$ & $0(0)$ & \\
\hline Proximal margin $(\mathrm{cm})^{\star}$ & $6(4.7-8.75)$ & $6.3(5.4-8.4)$ & $5(3.5-9.5)$ & 0.949 \\
\hline Distal margin $(\mathrm{cm})^{*}$ & $2(3-4)$ & $3.3(3-4.2)$ & $3(1.6-3.7)$ & 0.357 \\
\hline $\mathrm{CRM}(\mathrm{mm})^{\star}$ & $2(1-2.9)$ & $1.6(1-3)$ & $2(1.9-2.9)$ & 0.170 \\
\hline Proximal margin clear & $23(100)$ & $12(100)$ & $11(100)$ & \\
\hline Distal margin clear & $23(100)$ & $12(100)$ & $11(100)$ & \\
\hline Duke's staging & & & & 0.697 \\
\hline A & $5(21.7)$ & $2(16.7)$ & $3(27.3)$ & \\
\hline $\mathrm{B} 1$ & $6(26.1)$ & $4(33.3)$ & $3(27.3)$ & \\
\hline B2 & $4(17.4)$ & $3(25)$ & $1(9.1)$ & \\
\hline $\mathrm{C} 1$ & $5(21.7)$ & $3(25)$ & $2(18.2)$ & \\
\hline $\mathrm{C} 2$ & $3(13)$ & $0(0)$ & $2(18.2)$ & \\
\hline $\mathrm{D}$ & $0(0)$ & $0(0)$ & 0 90) & \\
\hline Distant metastasis & $5(21.7)$ & $3(13)$ & $2(18.2)$ & 0.925 \\
\hline $\begin{array}{l}\text { Neoadjuvant } \\
\text { chemotherapy }\end{array}$ & $5(21.7)$ & $2(16.7)$ & $3(27.3)$ & 0.816 \\
\hline $\begin{array}{l}\text { Neoadjuvant } \\
\text { radiotherapy }\end{array}$ & $2(8.7)$ & $1(8.3)$ & $1(9.1)$ & 0.943 \\
\hline
\end{tabular}

Values are presented as mean \pm standard deviation or median (interquartile range).

OAR, open anterior resection; LAAR, laparoscopic-assisted anterior resection; CRM, circumferential resection margin.

were $6.6 \pm 1.7 \mathrm{~cm}$ and $3.8 \pm 1 \mathrm{~cm}$, respectively, and in LAAR they were $7.8 \pm 4 \mathrm{~cm}$; and $4.1 \pm 2.9 \mathrm{~cm}$, respectively. The 2 rectosigmoid cancers proximal and distal margins in the open group were $8 \mathrm{~cm}$ and $3 \mathrm{~cm}$, respectively, and in the LAAR group, they were 4.4 $\mathrm{cm}$ and $5.3 \mathrm{~cm}$, respectively.

\section{DISCUSSION}

\section{Postoperative outcomes}

Colorectal cancer is the third leading cause of death in Malaysia and is the commonest cancer in both females and males in the 
developed nations of Europe, America, Asia, and Australia [4, 7]. The mainstay treatment remains resection of the tumor-bearing segment of the colon with wide tumor-free resection margins and systematic lymphadenectomy $[4,15]$. In respect to surgery details, patients who were subjected to laparoscopic surgery had to wait longer from the time of their first visit to the time of surgery. This is due to the necessity of the laparoscopic device energy, trocars, and bowel stapling devices. An application to purchase these devices was sought from the financial aid given by the Malaysian government cancer societies [16]. Therefore, the waiting time for surgery in these patients was longer. Although statistically insignificant and similar to published results, patients in the laparoscopic group had a shorter mean hospital stay of 1.5 days compared to patients in the open surgery group $[4,17]$. This is due to the earlier recovery of bowel function and reintroduction of oral feeding [18]. Cochrane analysis in 8 studies, which included 1,116 patients, revealed that the duration of postoperative ileus associated with postoperative return of bowel function was one day earlier than the open colorectal resection group [4]. Another important aspect is due to the lowered postoperative intake of analgesia and lung recovery. This is evidenced by a randomized control trial by Schwenk et al. [4] that showed superior forced vital capacity and forced expiratory volume in one second in patients who underwent laparoscopic colectomies. These results were more evident on postoperative day 3 which showed 131 patients with significant improvement in forced vital capacity [4]. Presumably due to the superior lung functions, which led to lower pulmonary complications (such as, atelectasis and pneumonia) and may explain the shorter mean hospital stay [4]. Other postulates of shorter hospital stay are due to the better preservation of systemic immune response caused by less tissue contact and injury in laparoscopic anterior resections [19]. Our results were statistically insignificant but showed a shorter length of stay. This is attributed to our small sample size. However, this showed the feasibility and potential benefits of laparoscopic surgery in our local surgical colorectal unit. We also audited the complication rates at our centre. Two recorded anastomotic leaks (8.7\%) and one deep organ space surgical site infection were seen in the OAR group. In the laparoscopic group, only 2 complications were recorded, which were a superficial site infection and enterocutaneous fistula. The anastomotic leak results were higher than in a publication by Hong et al. [13], which only recorded 4 anastomotic leaks ( $0.81 \%)$ from a total of 246 patients. We could not come to a solid conclusion from this result as this is a retrospective audit and patient selection was not standardized.

\section{Oncologic outcomes}

From our audit, we found that there were equivalent oncologic outcomes in both the laparoscopic and OAR group. From the histopathological results, tumor margin length (proximal and distal) and circumferential radial margin were almost identical in both the laparoscopic and open groups. All patients had a complete histopathological report. This result is similar to multiple studies and laparoscopic surgery is feasible with good surgical training in colorectal subspecialty [20]. West et al. [20] showed that the adoption of surgical education in central vascular ligation led to significant results, including a greater length of colonic specimen, greater distance between tumor and vascular tie and a higher yield of mesenteric lymph nodes $(\mathrm{P}<0.001)$. Throughout our study duration, there were no port site recurrences probably due to the short duration of follow-up and a small number of patients. A reported port site recurrence was seen in $1.9 \%$ of patients in a review of 163 patients and this was likely attributed to the traumatic manipulation of the specimen [21]. However, this can be prevented and reduced by tumor bagging and the use of the "notouch" isolation technique [22].

\section{Current penetration of laparoscopic colorectal surgery in Malaysia}

As of 2013, the incidence and mortality rates of colorectal cancer in Malaysia were 21.3 and 9.79 cases per 100,000 residents [7, 23]. The reported incidence and mortality rates of colorectal cancer were higher in the northern states of Malaysia with incidence and mortality rates of 53.18 and 23.07 cases per 100,000 residents. This number is high compared to an incidence rate of 43.7 cases per 100,000 residents in the US and 41.7 cases per 100,000 residents [23]. At present, there are numerous studies published on colorectal cancer in Malaysia [7]. These studies have shown similar demographic data to our results with a similar mean age group of 60-69 years, with Chinese patients and males being the majority of those diagnosed with colorectal cancer $[7,23]$. However, reports on laparoscopic colorectal surgery in Malaysia are lacking [7]. We could not find any information in the literature published in English on the number of laparoscopic surgeries performed in Malaysia. The only data found were from the Malaysian National Cancer Patient Registry in colorectal cancer [23]. This is the largest registry available but only contains data from 4 out of a total of 14 states in Malaysia. Despite the lack of participation from the majority of other states in Malaysia, this national initiative successfully harvested the records of 3,117 patients [23]. The data revealed that the majority of cancers were located at the sigmoid, rectosigmoid, and rectum (77\%). From the 4 states of Malaysia, an average of 66 laparoscopic operations per year were performed from 2008 till 2015 which accounts for $14.9 \%$ of the total surgeries performed for colorectal cancers. Despite the high number of patients, there were no detailed data with regard to the type of resection being performed laparoscopically [7,23]. This gives a rough estimate of the local penetration of laparoscopic surgery in Malaysia. Therefore, we hope that our study, which is from the southern state of Malaysia, may help consolidate and create awareness of local laparoscopic colorectal resection.

\section{Study limitations}

This is a retrospective audit which is liable to have missing data 
and bias as patient selection were not standardized. Our hospital still relies heavily on handwritten clinical notes; therefore, another reason for missing data or misinterpretation was due to poor handwriting. To overcome this, the sample population from the colorectal surgery database was only from 1 year (October 2017 to November 2018). The colorectal consultant and operating surgeon responsible for the majority of these cases prior to data entry was consulted if any clinical data were in doubt. Other notable limitations were the exclusion of patients who were converted to open surgery. These data were not captured as the main objective in this study was to compare the outcomes of open and laparoscopic anterior resection.

In conclusion, this retrospective audit suggests laparoscopic anterior resection is feasible in a local Malaysian colorectal surgery unit. The observed benefits were a shorter length of stay with equivalent oncologic results. This result is similar to those of other international studies. The results are valuable data and laparoscopic anterior resection should be offered to patients who fit the eligibility criteria in a well-trained colorectal surgery centre. In light of this data, we hope that this paper may create more awareness of laparoscopic colorectal surgery in Malaysia.

\section{CONFLICT OF INTEREST}

No potential conflict of interest relevant to this article was reported.

\section{ACKNOWLEDGMENTS}

Full acknowledgments are given to the colorectal coordinating nurse, Hidaryati Md Bamuchi, for dedicated data collection.

\section{REFERENCES}

1. Nussbaum DP, Speicher PJ, Ganapathi AM, Englum BR, Keenan JE, Mantyh CR, et al. Laparoscopic versus open low anterior resection for rectal cancer: results from the national cancer data base. J Gastrointest Surg 2015;19:124-31.

2. Alexander RJ, Jaques BC, Mitchell KG. Laparoscopically assisted colectomy and wound recurrence. Lancet 1993;341:249-50.

3. Böhm B, Milsom JW, Kitago K, Brand M, Stolfi VM, Fazio VW. Use of laparoscopic techniques in oncologic right colectomy in a canine model. Ann Surg Oncol 1995;2:6-13.

4. Schwenk W, Haase O, Neudecker J, Müller JM. Short term benefits for laparoscopic colorectal resection. Cochrane Database Syst Rev 2005:CD003145.

5. Bonjer HJ, Deijen CL, Haglind E; COLOR II Study Group. A randomized trial of laparoscopic versus open surgery for rectal cancer. N Engl J Med 2015;373:194.

6. Martínez-Pérez A, Carra MC, Brunetti F, de’Angelis N. Shortterm clinical outcomes of laparoscopic vs open rectal excision for rectal cancer: a systematic review and meta-analysis. World J
Gastroenterol 2017;23:7906-16.

7. Lim KG. A review of colorectal cancer research in malaysia. Med J Malaysia 2014;69 Suppl A:23-32.

8. West NP, Hohenberger W, Weber K, Perrakis A, Finan PJ, Quirke P. Complete mesocolic excision with central vascular ligation produces an oncologically superior specimen compared with standard surgery for carcinoma of the colon. J Clin Oncol 2010; 28:272-8

9. Luglio G, De Palma GD, Tarquini R, Giglio MC, Sollazzo V, Esposito $\mathrm{E}$, et al. Laparoscopic colorectal surgery in learning curve: role of implementation of a standardized technique and recovery protocol. A cohort study. Ann Med Surg (Lond) 2015;4:89-94.

10. Zhu QL, Feng B, Lu AG, Wang ML, Hu WG, Li JW, et al. Laparoscopic low anterior resection for rectal carcinoma: complications and management in 132 consecutive patients. World J Gastroenterol 2010;16:4605-10.

11. Law WL, Chu KW. Anterior resection for rectal cancer with mesorectal excision: a prospective evaluation of 622 patients. Ann Surg 2004;240:260-8.

12. Braga M, Vignali A, Gianotti L, Zuliani W, Radaelli G, Gruarin P, Dellabona et al. Laparoscopic versus open colorectal surgery: a randomized trial on short-term outcome. Ann Surg 2002;236: 759-66.

13. Hong D, Jeanine T, Mehran A. Laparoscopic vs. open resection for colorectal adenocarcinoma. Dis Colon Rectum2001;44:10-8.

14. Teeuwen PH, Bleichrodt RP, Strik C, Groenewoud JJ, Brinkert W, van Laarhoven CJ, et al. Enhanced recovery after surgery (ERAS) versus conventional postoperative care in colorectal surgery. J Gastrointest Surg 2010;14:88-95.

15. Magaji BA, Moy FM, Roslani AC, Law CW. Survival rates and predictors of survival among colorectal cancer patients in a Malaysian tertiary hospital. BMC Cancer 2017;17:339.

16. MAKNA Majlis Kanser Nasional (National Cancer Council) [Internet]. Kuala Lumpur (Malaysia): MAKNA Majlis Kanser Nasional (National Cancer Council); c2017 [cited 2019 Mar 3]. Available from: http://makna.org.my/.

17. Pędziwiatr M, Małczak P, Mizera M, Witowski J, Torbicz G, Major $\mathrm{P}$, et al. There is no difference in outcome between laparoscopic and open surgery for rectal cancer: a systematic review and meta-analysis on short- and long-term oncologic outcomes. Tech Coloproctol 2017;21:595-604.

18. Wexner SD, Reissman P, Pfeifer J, Bernstein M, Geron N. Laparoscopic colorectal surgery: analysis of 140 cases. Surg Endosc 1996; 10:133-6.

19. Hewitt PM, Ip SM, Kwok SP, Somers SS, Li K, Leung KL, et al. Laparoscopic-assisted vs. open surgery for colorectal cancer: comparative study of immune effects. Dis Colon Rectum 1998;41: 901-9.

20. West NP, Sutton KM, Ingeholm P, Hagemann-Madsen RH, Hohenberger W, Quirke P. Improving the quality of colon cancer surgery through a surgical education program. Dis Colon Rectum 2010;53:1594-603. 
21. Melotti G, Tamborrino E, Lazzaretti MG, Bonilauri S, Mecheri F, Piccoli M. Laparoscopic surgery for colorectal cancer. Semin Surg Oncol 1999;16:332-6.

22. Shukla PJ, Barreto G, Gupta P, Shrikhande SV. Laparoscopic surgery for colorectal cancers: Current status. J Minim Access Surg 2006;2:205-10.
23. National Cancer Patient Registry - Colorectal Cancer. Report for the Norther Region of Malaysia (2008-2014) [Internet]. Kedah (Malaysia): Ministry of Health Malaysia Clinical Research Centre; 2017 [cited 2019 Apr 23]. Available from: http://www.crc.gov. my/wp-content/uploads/documents/report/NCPR2014.pdf. 